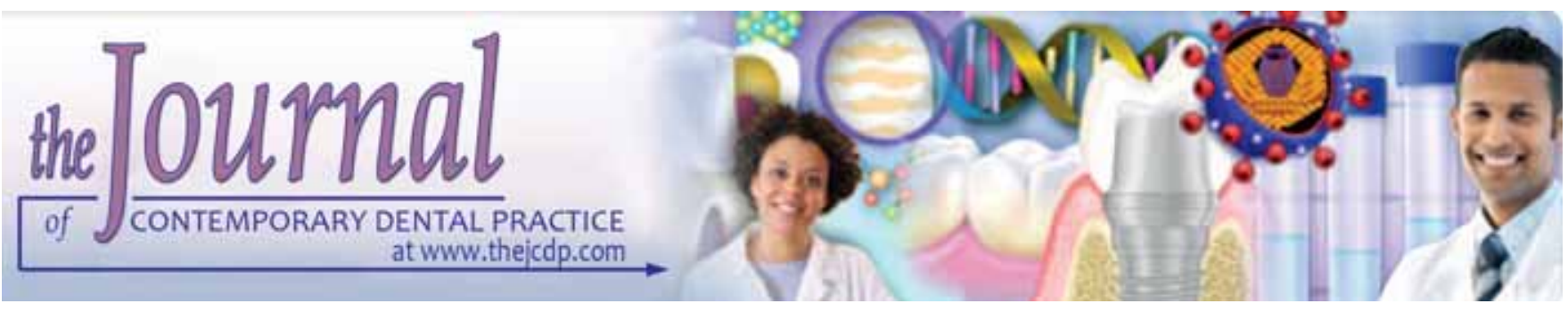

\title{
Evaluation of Two Methods in Controlling Dental Treatment Water Contamination
}

\author{
Ritu Bansal, Raghunath Puttaiah, Robert Harris, Anil Reddy
}

\begin{abstract}
Dental unit water systems are contaminated with biofilms that amplify bacterial counts in dental treatment water in excess of a million colony forming units per milliliter (cfu/ml). The Centers for Disease Control and Prevention and the American Dental Association have agreed that the maximum allowable contamination of dental treatment water not exceed $500 \mathrm{cfu} / \mathrm{ml}$. This study was conducted to evaluate two protocols in controlling contamination of dental unit water systems and dental treatment water. Both methods used an antimicrobial self-dissolving chlorine dioxide $\left(\mathrm{ClO}_{2}\right)$ tablet at a high concentration (50 ppm) to shock the dental unit water system biofilms initially followed by periodic exposure. To treat dental treatment source water for patient care, 3 parts per million (ppm) $\mathrm{ClO}_{2}$ in municipal/tap water was compared to use of a citrus botanical extract dissolved in municipal water. Heterotrophic microbial counts of effluent water and laser scanning confocal microscopy were performed to evaluate effects of the two treatments. Results from this study indicated that both treatments were effective in controlling biofilm contamination and reducing heterotrophic plate counts $<500 \mathrm{cfu} / \mathrm{ml}$. A comprehensive study addressing compatibility of $50 \mathrm{ppm} \mathrm{ClO}_{2}$ on the metals and nonmetal components of the dental water system and effects of low-grade chemicals used on composite bonding to dentin and enamel is warranted before translation from efficacy studies to common clinical use.
\end{abstract}

Clinical significance: This study provides evidence-based information of using two methods of controlling dental treatment water contamination. The study was conducted in a clinical practice setting in an active dental clinic and the results are meaningful to a clinician who is interested in providing safe dental treatment water for patient care.

Keywords: Dental waterline biofilms, Dental treatment water contamination control, Chlorine dioxide, Emulsifiers, Heterotrophic plate counts, Laser scanning confocal microscopy.

How to cite this article: Bansal R, Puttaiah R, Harris R, Reddy A. Evaluation of Two Methods in Controlling Dental Treatment Water Contamination. J Contemp Dent Pract 2011;12(2):73-83.

Source of support: Nil

Conflict of interest: None declared

\section{OBJECTIVES}

1. To study the effects of $50 \mathrm{ppm}$ active chlorine dioxide periodic decontaminating agent in controlling biofilms and inorganic deposits found in dental unit water system.

2. To study the effects of 2 to 3 ppm active chlorine dioxide in municipal water as an irrigant.

3. To study the effects of a citrus botanical emulsifier in municipal water as an irrigant.

\section{BACKGROUND}

Biofilms are routinely found in dental unit water (DUW) and are formed when planktonic bacteria adhere to the inner lumenal walls of water lines within dental treatment water delivery systems. ${ }^{1}$ In aquatic environments, such as dental unit waterlines (DUWLs), macromolecules and other lowmolecular-weight hydrophobic molecules may adsorb to the line surfaces forming conditioning films. Planktonic bacteria from the water adhere to these conditioning films, laying the basis for a mature biofilm matrix. ${ }^{2}$ Some bacteria may immediately form a firm but passive attachment to the surface, while others become attached in a more active adhesion process through secretion of exopolysaccharide glycocalyx polymers, which serve to anchor the biofilms to the surface. ${ }^{3}$ Biofilm growth has been observed inside dental unit plastic waterlines in as little as two weeks. ${ }^{4}$ Biofilms, when viewed through a scanning electron microscope (SEM), were found to be characterized by microorganisms embedded in a matrix. This matrix ranging from 30 to 50 microns in thickness may allow chunks of material/biofilm to dislodge, thereby contaminating other areas of the dental treatment water system and dental treatment water. ${ }^{5}$

Note: This study was conducted as a part of Dr Bansal's internship requirements for the masters in Public Health graduate degree program. 
Colonization in DUW and DUWLs by many species of microorganisms has been well documented. ${ }^{6-13}$ Although many microorganisms found in this environment may be potentially pathogenic, three genera in particular are of concern for the dental office, Pseudomonas, Mycobacteria and Legionella. Pseudomonas cepacia (Gram-negative bacillus) has been spread to patients in hospital settings through its presence in aqueous disinfectants. ${ }^{14,15}$ This species is very resistant to common chemical germicides and has been implicated in contamination when reservoirs of chlorhexidine gluconate have been 'topped-up' without cleaning the reservoirs first. ${ }^{14-18}$ Several species of Mycobacterium have been isolated from hospital water supplies, some of which have been associated with hospital related infections. ${ }^{19-22}$ In one case, $M$. xenopi was implicated in 19 cases of pulmonary disease in a Veterans Administration Hospital. ${ }^{21}$ The transmission occurred through infectious aerosols when patients used a shower. Water spray aerosols are commonplace in the dental setting (high-speed handpiece operation, utilization of ultrasonic scalers and spraying with air water syringe). While studies addressing morbidity and mortality associated with dental treatment water contamination are lacking and next to impossible to conduct, clinical-epidemiological studies have indicated that aerosols generated by the water cooling component of dental handpieces were found to be the source of subclinical infection (including sensitization) with Legionella pneumophila in a dental school environment. ${ }^{11}$ Fotos et $\mathrm{al}^{23}$ investigated exposure of students and employees at a dental clinic and found that of the 270 sera tested, $20 \%$ had significantly higher IgG antibody activity to the pooled Legionella $s p$ antigen as compared with known negative controls. Reinthaler et $\mathrm{al}^{24}$ found a high prevalence of antibodies to Legionella pneumophila among dental personnel. Their study demonstrated the highest prevalence (50\%) among dentists who were frequently exposed to the aerosols generated when high-speed drills and sprays were used. Atlas et $\mathrm{al}^{25}$ found that $68 \%$ of DUW samples collected from 28 dental facilities in six states in the United States of America, showed presence of the Legionella species. This study also reported that $61 \%$ of water samples from institutional faucets and drinking water fountains also contained species of Legionella.

Several methods have been suggested by which the contamination of DUWs could be minimized or avoided. Many dental units today are equipped with antiretraction values to prevent suck-back and/or are designed to give a short 'terminal flush' of water through handpieces after operation. ${ }^{26}$ Flushing of DUWLs at the beginning and end of patient treatment has been previously advocated. ${ }^{27,28}$ Suggested flushing protocol, as recommended by the US Department of Health and Human Services ${ }^{29}$ may diminish planktonic organisms but will not eliminate or control biofilms. One study concluded that a two-minute flushing reduced the counts of planktonic organisms, on average by one-third, but did not reduce counts to zero. ${ }^{30}$ Many authors have suggested flushing waterlines with various disinfectant solutions, which include hydrogen peroxide, ${ }^{31}$ chlorhexidine gluconate, ${ }^{32}$ sodium hypochlorite, ${ }^{33}$ povidone-iodine ${ }^{13}$ and mouthwash. ${ }^{34}$ Each of these methods, though effective at controlling biofilms and planktonic organisms, does not eliminate biofilms formation due to the inherent contamination of source or city water supplies.

The microbial quality and mineral content of tap water varies depending upon the processing, distance from the processing plant, inherent mineral content and seasonal variations. Purely by cleaning/disinfecting the lines periodically, one cannot ensure that tap water can meet the ADA's goal. The ADA's statement on dental unit waterlines implies that there must be a control over the quality of water to be used in the event of 'boil water alerts' in the community. One way to control contamination would be to retrofit the DUW system with a self-contained reservoir and detach the water system from the municipal water source. As of today, there are many self-contained water systems ranging in volume of water, function and costs.

Tap water can be treated in a variety of ways to provide treatment water, which will meet the ADA's goal. Boiling, pasteurization, filtration, distillation, sterilization and utilization of chemical additives (approved germicides in countries and regions of use by regulatory bodies) are some of the methods which may be efficacious in controlling the level of contamination in tap water. Some filters (activated carbon casing fused to a high intensity UV light) have been used to improve source water. ${ }^{35}$ Commercially produced distilled and bottled water are not microbiologically consistent or reliable for dental use.

Biofilm contamination is a dynamic process due to many factors. Some of the main factors are: (1) Long periods of stagnation; (2) high surface to volume ratio; (3) nutritional content of water for the microbial survival; (4) mineral content and hardness of water facilitating coating of the lumen; (5) fluid dynamics (laminar flow); (6) low flow rate; and (7) microbial quality of the water entering the system. Purely flushing the water for a few minutes prior to treatment is not effective in biofilm removal, while it may reduce planktonic organisms for a short period. Exposure of the patient to certain microbial forms associated with respiratory and enteric diseases may be very plausible if the water quality is poor. The types of organisms may range from Legionella to E. coli which may inherently be seen in dental units rigged to municipal water or which may be contaminated by handlers of the self-contained reservoirs if proper hygiene practices/glove-use not followed. When 
such outbreaks are found in a dental clinic, it may well result in medical-legal problems. Aerosol contamination leading to respiratory problems among the clinic staff can also be reduced if water lines are maintained and regularly cleaned.

There are many physical and chemical methods of improving dental treatment water quality. Today, membrane filters, antimicrobial impregnated filters/cartridges and membrane filters which have the capability of controlling water microbes and endotoxins, are being marketed for dental waterline use. Most available membrane filters are consistent in controlling microbes/planktonic microorganisms in dental treatment water, ${ }^{36}$ while membrane filters with the additional function of endotoxin retention are even more beneficial. When using filters, it may be pragmatic to periodically control the biofilm in the DUW systems to reduce the bacterial and endotoxin challenge to the filters. Furthermore, it is absolutely essential to change the filters based on the manufacturers' recommended optimal performance life. Chemical treatment or constantly present chemicals to control the microbes and biofilms in DUWLs are some of the options available to dentists. While selecting chemicals, it is necessary to use safe and approved chemicals or safe methods in treating waterlines. The chemicals selected must be approved by the FDA for use in the jurisdiction of the United States, safe for patients, noncorrosive to the components of the DUW system and compatible with other materials used in the patient's mouth. One such example is low concentration of constantly present citric acid in the DUW system used as an irrigant [classified as GRAS (generally recognized as safe)]. ${ }^{37}$ Other examples are chlorhexidine ${ }^{38}$ and elemental iodine. Chlorine dioxide has shown benefits in controlling the waterline biofilms and dental treatment water contamination when used with pasteurized water for dental treatment purposes. ${ }^{40}$

Use of sodium hypochlorite $(\mathrm{NaOCl})$ is very effective in biofilm control and improving dental treatment water quality, but there are drawbacks. $\mathrm{NaOCl}$ is very corrosive and can be damaging to the DUW system. High amounts of trihalomethanes are produced when in contact with organic matter such as biofilms. ${ }^{39}$ Constantly present low concentrations of $\mathrm{NaOCl}$ in the presence of organic matter also increase the total trihalomethane levels beyond levels set by the US Environmental Protection Agency. ${ }^{39}$ The US FDA has not approved the use of $\mathrm{NaOCl}$ for the specified purpose of cleaning DUWLs. Safety and efficacy of chlorine dioxcide was addressed in a document published by the Concise International Chemical Assessment Documents (CICADs), ${ }^{41}$ in a family of publications from the International Programme on Chemical Safety (IPCS) a cooperative program of the World Health Organization (WHO), the International Labor Organization (ILO), and the United Nations Environment Program (UNEP). CICADs are a part of the environmental health criteria documents (EHCs) as authoritative documents on the risk assessment of chemicals. Chlorine dioxide gas dissolved in water was found to be relatively safe to humans per CICADs. Furthermore, chlorine dioxide gas dissolved in water has been used for many decades and shown to be effective as a high-level disinfectant or sterilant in context of use, method, concentration, duration of contact and purpose. ${ }^{42}$ Fact sheets from the US $\mathrm{EPA}^{42}$ state that chlorine dioxide $\left(\mathrm{ClO}_{2}\right)$ is an antimicrobial pesticide recognized for its disinfectant properties since the early 1900s. Antimicrobial pesticides are substances used to control harmful microorganisms including bacteria, viruses or fungi on inanimate objects and surfaces. In 1967, EPA first registered the liquid form of chlorine dioxide for use as a disinfectant and sanitizer. In 1988, EPA registered chlorine dioxide gas as a sterilant.

Currently, this chemical is approved for use in Federal Anthrax Decontaminating Efforts. The pesticide label provides specific safety precautions and use directions for handling or using the product. EPA has concluded that chlorine dioxide products registered to date have met federal standards for environmental and human health safety. EPA first registered chlorine dioxide gas as an antimicrobial pesticide in the 1980s. Chlorine dioxide gas is registered for sterilizing manufacturing and laboratory equipment, environmental surfaces, tools and clean rooms. It is also used in pharmaceutical research and production. Liquid chlorine dioxide formulations were first registered in the 1960s as disinfectants and are used on a variety of sites including pets; farm animals; bottling plants; food processing, handling and storage plants; and many others. Pesticide products containing either sodium chlorite or stabilized chlorine dioxide are usually mixed with another 'reactive' chemical, usually an acid, to produce chlorine dioxide in a liquid or gaseous state. The CDC in their Emerging Infectious Disease Section found that $\mathrm{ClO}_{2}$ was one among the disinfectants that could be used to inactivate Bacillus anthracis spores. ${ }^{43}$ Self-dissolving chlorine dioxide tablets (MB-10 Tablets $\left.{ }^{\circledR}\right)^{44}$ developed by Engelhard Corporation and being marketed by Quip Laboratories Inc. 1500 Eastlawn Ave, Wilmington, DE 19802, USA as a germicide (EPA Reg. No. 70060-19-46269; EPA Est. No. 46269-DE-01) for use in hospitals, medical, dental, industrial, manufacturing and institutional facilities, laboratory animal facilities, clinical and research laboratories, veterinary hospitals and clinics and animal rearing and confinement facilities. This product can be used as a food-contact surface sanitizer where $50 \mathrm{ppm} \mathrm{ClO}_{2}$ can be applied to surfaces for 60 seconds with draining and no rinsing. Chlorine dioxide was shown to be efficacious as a disinfectant in a quantitative suspension test carried out under both clean and dirty conditions to assess the activity 
of various instrument and environmental disinfectants against the type strain NCTC 946 and an endoscope washer disinfector isolate of Mycobacterium chelonae, Mycobacterium fortuitum NCTC 10394, Mycobacterium tuberculosis H37 Rv NCTC 7416 and a clinical isolate of Mycobacterium avium-intracellulare (MAI). ${ }^{45} \mathrm{ClO}_{2}$ has shown efficacy as a disinfectant where in vitro suspension tests showed about $140 \mathrm{ppm}$ of $\mathrm{ClO}_{2}$ reduced 106 Staphylococcus aureus in 1 minute even in the presence of $3 \mathrm{~g} / \mathrm{l}$ bovine albumin. ${ }^{46}$

Self-dissolving chlorine dioxide periodic cleaning tablets (Aseptrol, Engelhard Corporation, Iselin, New Jersey, USA $)^{47,48}$ was used in an in vitro study to assess its effects on biofilm control and irrigant water contamination control using an automated dental unit water system simulator. This automated dental unit water system simulator was designed and built to scale and function simulating eight dental unit water systems and was operated using logic controllers which in turn was signaled by algorithms to simulate dental water system usage in general dental practice. ${ }^{49}$ Biofilms were naturally grown over 1 to 2 years period, or lines with mature biofilms and inorganic deposits harvested from older dental units retrofitted to the system.

In this study, we tested the same $50 \mathrm{ppm}$ of chlorine dioxide $^{47}$ as a periodic cleaning agent (Aseptrol Tab EPA Reg\#:70060-19; Registrant: Engelhard Corp; active ingredients sodium chlorite $20.8 \%$ and sodium dichloroisocyanurate dihydrate $7.0 \%$ ), 3 ppm chlorine dioxide ${ }^{47}$ as a decontaminating agent for irrigant municipal water. VistaClean 5 drops of concentrated citrus botanical ${ }^{49}$ in $700 \mathrm{ml}$ of municipal water (purpose as an emulsifying and scale control agent) was used as the irrigant in the second treatment unit. Both the $3 \mathrm{ppm} \mathrm{ClO}_{2}$ and the citrus botanical in municipal water were previously tested and found compatible with composite restorations bonding to dentin and enamel. ${ }^{50,51}$ VistaClean ${ }^{*}$ Irrigant Solution Concentrate is an FDA-cleared class I medical device derived from organically certified citrus, USP glycerol and UPS ascorbic acid. As an aqueous cleaner, it has the ability to emulsify organic and inorganic contaminants, soils and oxidation products. It provides lubrication as an irrigant while also protecting waterlines and system components from deposits and scale. VistaClean may be used in waterlines in contact with patients continuously or intermittently as desired. When used according to directions, it is completely nontoxic, safe for the environment, noncorrosive, simple to use and has no negative effect on bond strength. When VistaClean is used in low concentration as an irrigant during dental procedures, it provides additional lubrication required for instruments and cooling of the teeth while also emulsifying contaminants. Used in high concentration, VistaClean provides powerful cleaning characteristics. The citrus components of the food grade formula provide extraordinary cleaning and solvency characteristics as are common to today's citrus-based cleaners used for degreasing and general cleaning. The glycerol serves as a surfactant/wetting agent that lowers the surface tension of the water. Glycerol is commonly used in aqueous cleaners to provide detergency, emulsification and wetting action. Further, it can emulsify oily soils, films and metal salts keeping them dispersed and suspended, so they do not settle back on the internal system surfaces. The ascorbic acid is added to lower the $\mathrm{pH}$ that helps the cleaning process. The contaminants can then be loosened and removed with the aid of highspeed water and airflow during the maintenance procedure.

\section{METHODS}

Three dental units with self-contained water systems were used in this study. All three units had water systems that had not been cleaned for over 5 years. This study was conducted over a period of 12 weeks.

\section{Heterotrophic Plate Counts}

Water samples were collected at baseline (preinitial cleaning and postinitial cleaning) and weekly for 12 weeks for heterotrophic plate counts (HPC). Effluent and source water collected was diluted with sterile buffered water at 1:10, 1:100 and 1:1000 and plated on R2A agar, incubated at room temperature for 7 days. HPCs were made and if colonies exceeded 400 per plate, it was considered to be too numerous to count or counts from the next level of dilution would be used. All water samples were neutralized using 1 mol sodium thiosulphate before plating.

\section{Scanning Laser Confocal Microscopy}

One centimeter line samples were collected at baseline, midway (6 weeks) and end of study from all units. Line samples were also collected from the treatment units postinitial cleaning. The lines were immediately processed (within a few minutes after harvesting to maintain viability of live cells in the biofilms). Line samples were analyzed for biofilms using scanning laser confocal microscopy after staining with Baclight ${ }^{\mathrm{TM}}$ Green and Red (Molecular Probes Inc). Composite image of multilayer scan and topographical representation of the scan surface of each sample was used for qualitative analysis. Quantitative analysis of the scan was conducted by utilizing the quantitative report generated

*EPA publication ‘Guide to Cleaner Technologies’ (EPA/625/R-93/016 February 1994). Surfactants and Oleochemicals, Great Vista Chemicals Company, http://www.greatvistachemicals.com/surfactants_and_oleochemicals/ 
by the Leica Microsystems Software. Nonstandardized channel graphs of live and dead and mean energy uptake (live and dead). A new method for reduction or increase in biofilm was developed by using mean live (green dye) uptake divided by mean dead (red dye) uptake. In this study this would be called the biofilm viability ratio $(\mathrm{Vr})$. The $\mathrm{Vr}$ would be used to determine the reduction in biofilms. The best case scenario (presence of least contamination) was used for the control groups, while the worst case scenario (presence of most contamination) was used for the treatment groups as perfect representative area scans are next to impossible due to the diversity of the biofilms within each $1 \mathrm{~cm}$ line specimen (a very conservative method).

Unit 1 and unit 2 were used actively for patient care, while unit 3 was seldom used for patient care except as a recovery chair for patients after procedures. Following was the protocol:

- Unit 1 (treatment 1): Four initial 5 minutes contact with $50 \mathrm{ppm}$ active $\mathrm{ClO}_{2}$ followed by flush with $700 \mathrm{ml}$ municipal water to remove initial contamination and thereafter at about 45 days into the 90 days study. Irrigant used was about $3 \mathrm{ppm}$ active $\mathrm{ClO}_{2}$ and premixed in $700 \mathrm{ml}$ municipal water. Bottles containing unused irrigant were emptied out every two days and new irrigant mixed for the next day's use. Weekly, water samples plated on R2A for heterotrophic plate counts after being neutralized with sodium thiosulphate. Each sample was plated in triplicate. Midway and end of study line samples were harvested for scanning laser confocal microscopy.

- Unit 2 (treatment 2): Four initial 5 minutes contact with 50 ppm active $\mathrm{ClO}_{2}$ followed by flush with $700 \mathrm{ml}$ municipal water to remove initial contamination and thereafter at about 45 days into the 90 days study. Irrigant used was 4 to 5 drops of a citrus botanical (food-grade) mixed in $700 \mathrm{ml}$ municipal water. Bottles containing unused irrigant were emptied out every two days and new irrigant mixed for the next day’s use. Weekly, water samples plated on R2A for heterotrophic plate counts after being neutralized with sodium thiosulphate. Each sample was plated in triplicate. Midway and end of study line samples were harvested for scanning laser confocal microscopy.

- Unit 3 (control): Flush with $700 \mathrm{ml}$ distilled water with no other chemical treatment. Irrigant used was commercially sold distilled water. Weekly, water samples plated on R2A for heterotrophic plate counts after being neutralized with sodium thiosulphate. Each sample was plated in triplicate. Midway and end of study line samples were harvested for scanning laser confocal microscopy.

\section{RESULTS}

Table 1 lists the absolute heterotrophic plate counts of source and effluent water of the different study groups. Figure 1 shows the $\log _{10}$ values and the absolute counts seen in Table 1. Figures 1 to 4 are in detail and self-explanatory. Figure 1 shows the contamination measures of the source water and effluent water (both treatments) longitudinally over 12 weeks of the study. Figures $2 \mathrm{~A}$ to F represent scanning laser confocal microscopy results of treatment unit 1 (micrographs, topographical representation as well as

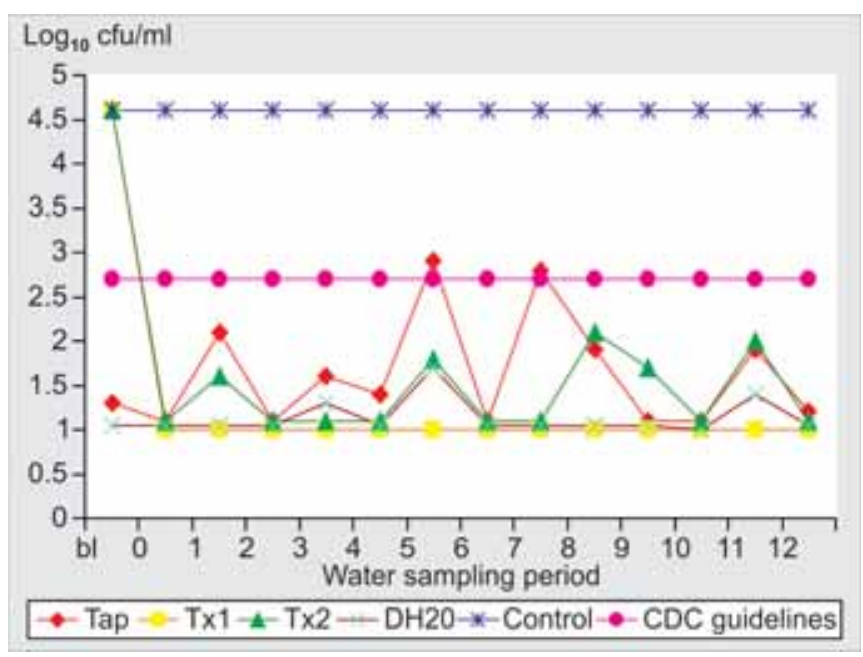

Fig. 1: Heterotrophic plate counts of source and effluent water in $\log _{10} \mathrm{cfu} / \mathrm{ml}$

\begin{tabular}{cccccc}
\multicolumn{5}{c}{ Table 1: Heterotrophic plate counts (cfu/ml) of source and effluent water/irrigants } \\
\hline Weekly sample & Tap water (mean) & TX1 (mean) & TX2 (mean) & Distilled water (mean) & Control (mean) \\
\hline Baseline & 20 & $>40,000$ & $>40,000$ & $<10$ & $>40,000$ \\
Postclean & 10 & $<10$ & 10 & 10 & $>40,000$ \\
1 & 130 & $<10$ & 40 & $<10$ & $>40,000$ \\
2 & $<10$ & $<10$ & $<10$ & $<10$ & $>40,000$ \\
3 & 40 & $<10$ & 10 & 20 & $>40,000$ \\
4 & 30 & 10 & 10 & $>40,000$ \\
5 & 860 & $<10$ & $<0$ & $>40,000$ \\
6 & 10 & $<10$ & $<10$ & $<10$ & $>40,000$ \\
7 & 570 & $<10$ & 10 & 10 & $>40,000$ \\
8 & 80 & 10 & $<0$ & $<10$ & $>40,000$ \\
9 & 10 & $<10$ & 10 & $>10$ & $>40,000$ \\
10 & $<10$ & $<10$ & 10 & 40 & $>40,000$ \\
11 & 80 & 30 & & 10 & $>40,000$ \\
\end{tabular}




\section{Scanning Laser Confocal Microscopy}

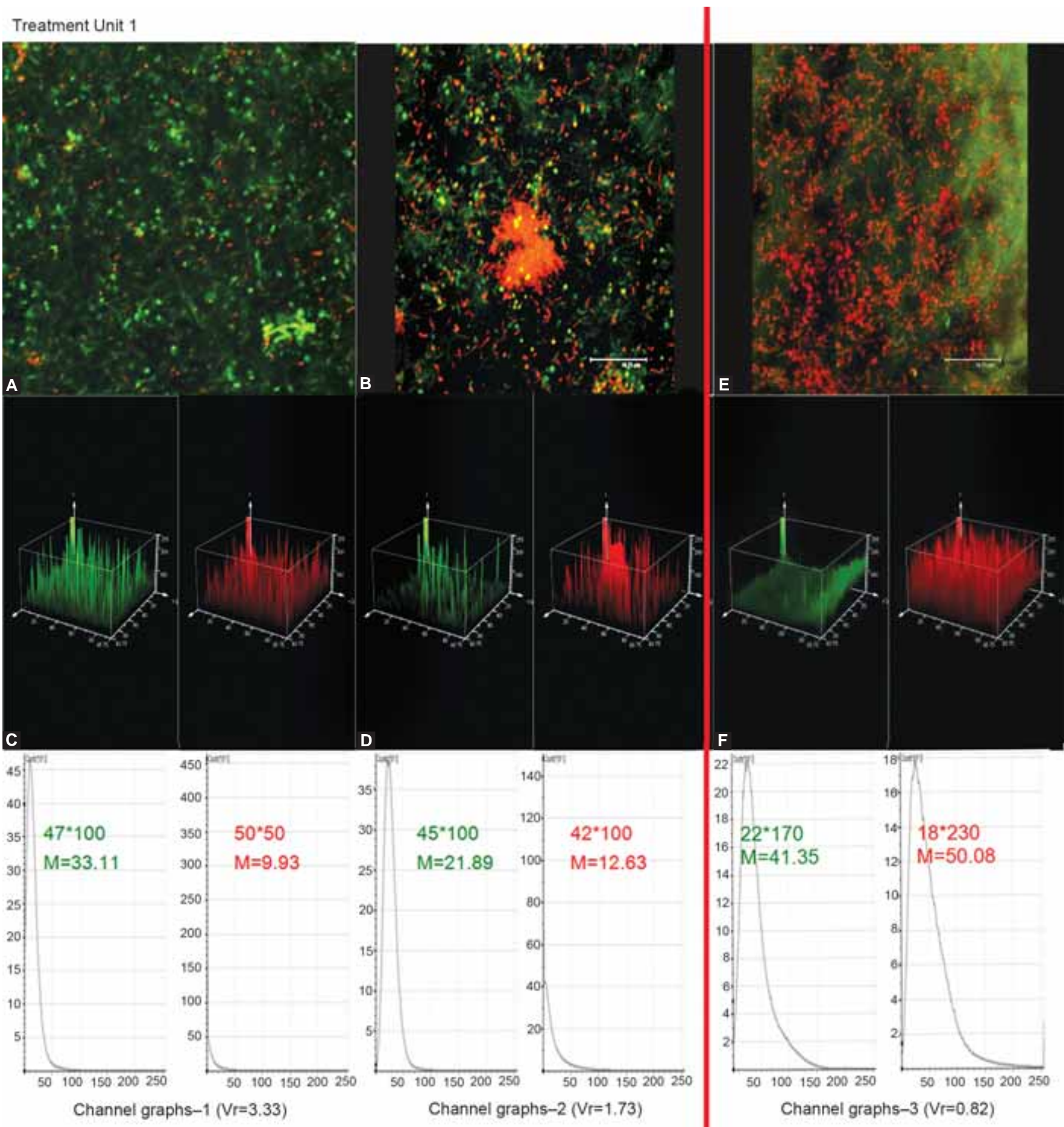

Figs 2A to F: (A) Treatment unit 1 at baseline before cleaning demonstrating a mature biofilm matrix seen with live (green) and dead (red) microbes. (B) Treatment unit 1, after initial cleaning showing reduction in biofilms. (C) Topographic representation of presence of mature biofilm in baseline sample. (D) Topographic representation of biofilm disrupted after initial treatment. (E) Treatment unit 1 at the end of 12 weeks with one periodic cleaning at week 6 still shows presence of dead microbes while controlling proliferation of biofilm. (F) Topographic representation of the scanned surface (E) showing control of biofilm with more red than green. Channel graphs of the three images show graphic representation of the scans. Vr from Ghannel graphs show a steady decrease $(3.33>1.73>0.82)$ representing a decrease in viable cells vs dead cells in the scanned area

channel graphs of absorption of green and red dye, i.e. live and dead microbes in the biofilms). Figures $3 \mathrm{~A}$ to $\mathrm{F}$ represent scanning laser confocal microscopy results of treatment unit 2 (micrographs, topographical representation as well as channel graphs of absorption of green and red dye, i.e. live and dead microbes in the biofilms). Figures $4 \mathrm{~A}$ to D represent scanning laser confocal microscopy results of the control unit (micrographs, topographical representation 


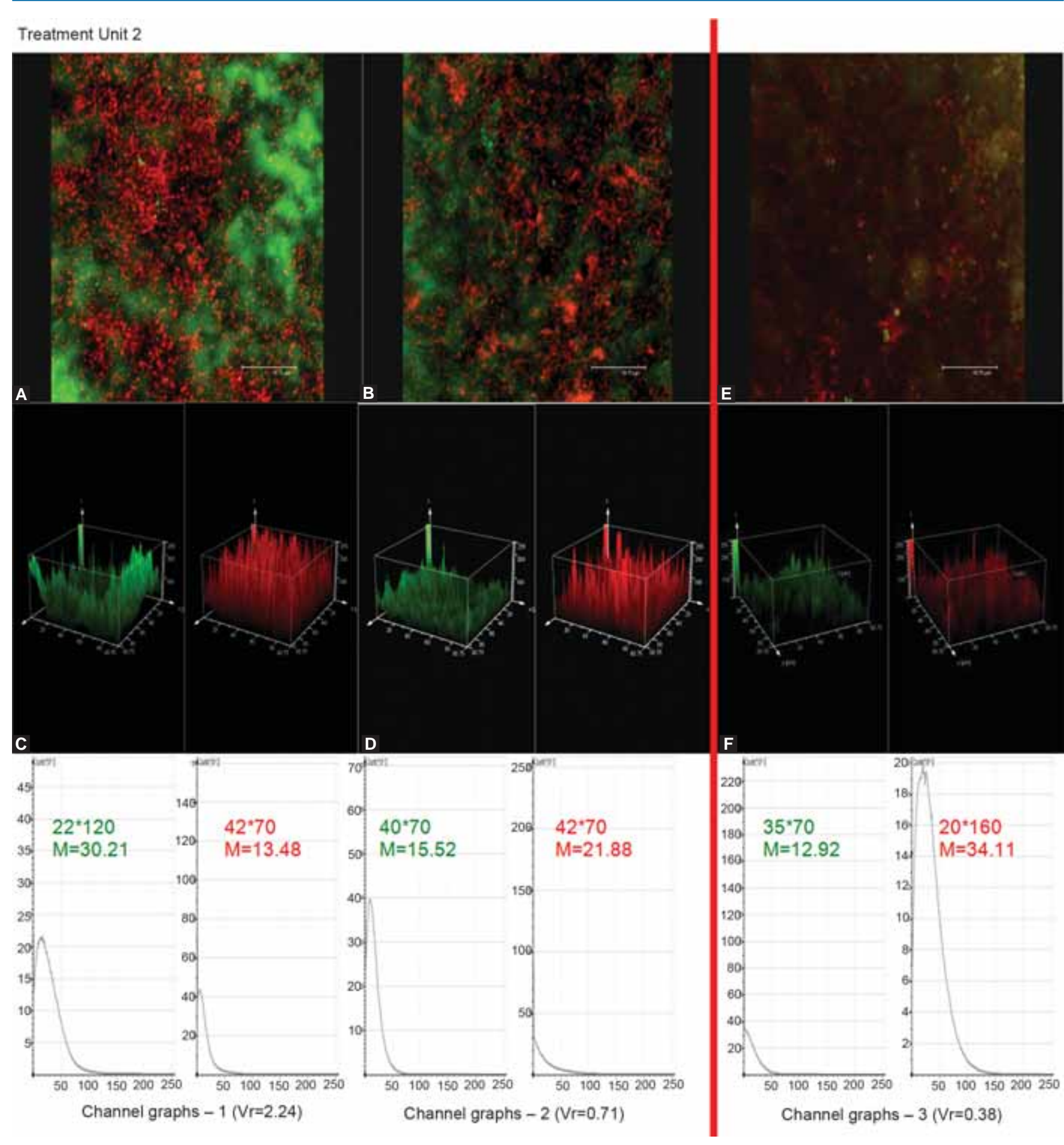

Figs 3A to F: (A) Treatment Unit 2 at baseline before cleaning demonstrating a mature biofilm matrix seen with live (green) and dead (red) microbes. (B) Treatment Unit 2, after initial cleaning showing reduction in biofilms. (C) Topographic representation of presence of mature biofilm in baseline sample. (D) Topographic representation of biofilm disrupted after initial treatment. (E) Treatment Unit 1 at the end of 12 weeks with one periodic cleaning at week 6 still shows presence of dead microbes while controlling proliferation of biofilm. (F) Topographic representation of the scanned surface $(E)$ showing control of biofilm with reduction of both red and green. Channel Graphs of the three images show graphic representation of the scans. Vr from channel graphs show a steady decrease $(2.24>0.71>$ 0.38 ) representing a decrease in viable cells vs dead cells in the scanned areas

as well as channel graphs of absorption of green and red dye, i.e. live and dead microbes in the biofilms). All graphs are quantified using channel graphs with ratios of live to dead dye uptake and could be a surrogate quantification measure of presence or absence of live and or dead cells in the field being viewed.

\section{DISCUSSION}

In previous in vitro studies using a combination approach of a high concentration of chlorine dioxide (30-40 ppm) as a periodic cleaner to control biofilms, and a low concentration (2-3 ppm) to control treatment water 

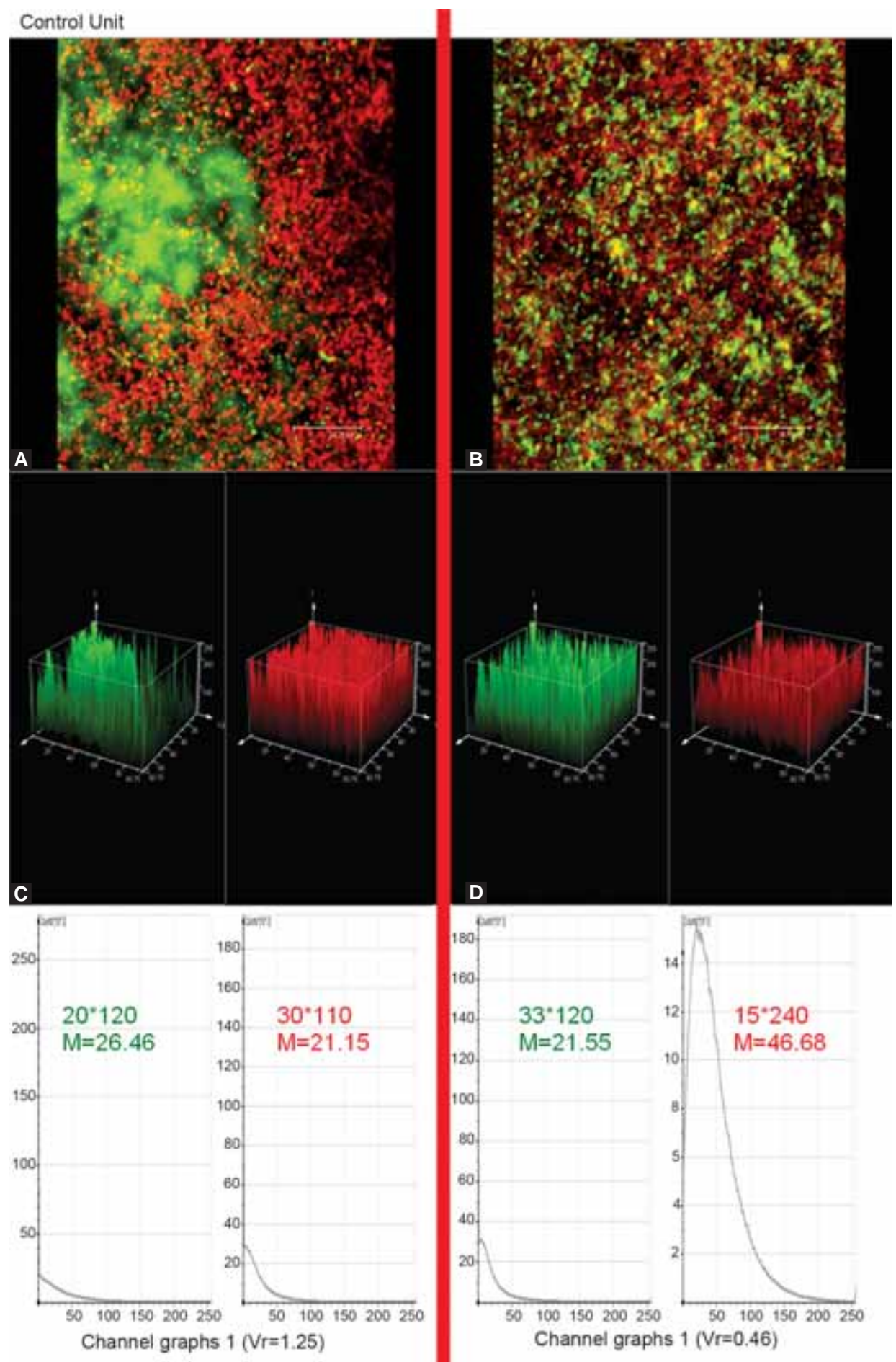

Figs 4A to D: (A) Control unit at baseline before cleaning demonstrating a mature biofilm matrix seen with live (green) and dead (red) microbes. (B) Control unit at the end of the study showing no change in biofilm status. (C) Topographic representation of presence of mature biofilm in baseline sample. (D) Topographic representation of biofilm showing no reduction in green uptake at the end of the study. Channel graphs of the two images show graphic representation of the scans. Vr from channel graphs show a decrease $(1.25>0.46)$ representing a decrease in viable cells vs dead cells in the scanned area

contamination. ${ }^{47,48}$ This preliminary study was conducted on a simulation system (Fig. 5) to study the safety of the decontamination agents with respect to the dental unit water system prior to being translated from controlled laboratory protocols to the chaotic clinical arena that has lesser controls.
Efficacy that is seen in the laboratory protocols get diluted when translated into clinical applications. In these studies a more rigorous protocol of initial cleaning followed by weekly cleaning was utilized to control biofilm and inorganic deposits on waterlines in an automated dental unit water system simulation device. Figures $6 \mathrm{~A}$ and $\mathrm{B}$ from 


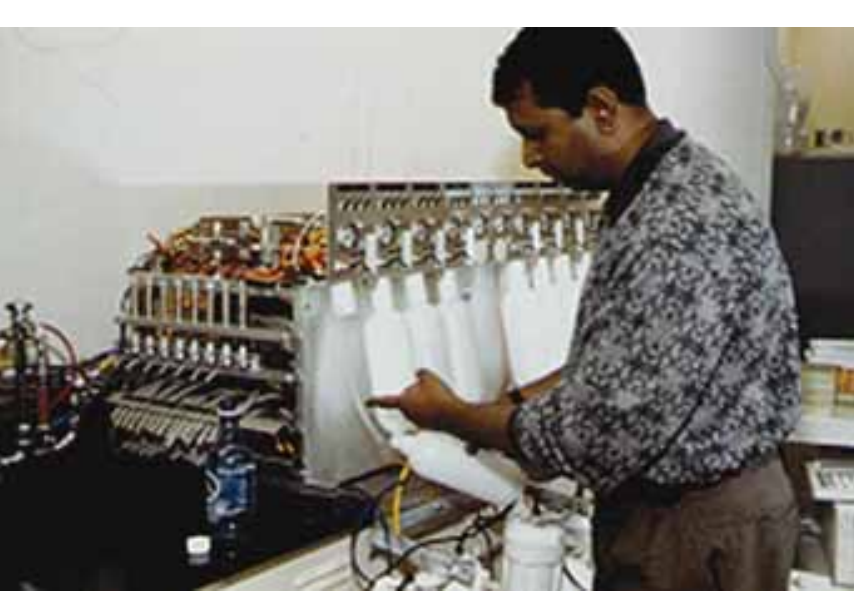

Fig. 5: The Automated Dental Unit Water System Simulation device that is used for in vitro studies on potentially corrosive or chemicals that may affect dental unit water system

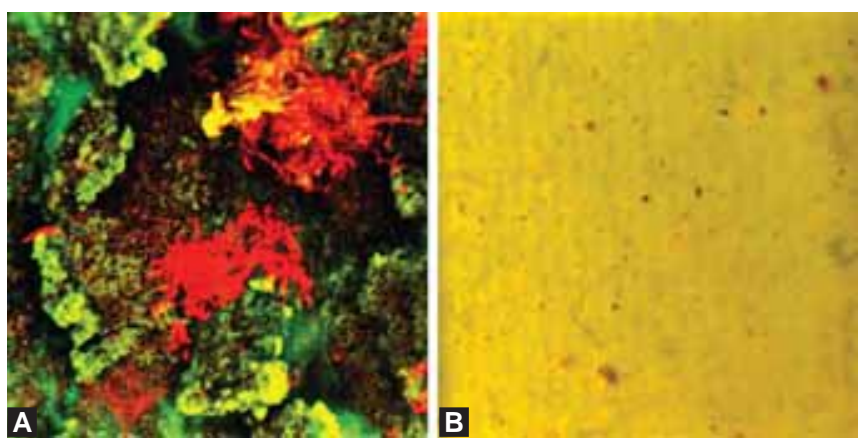

Figs 6A and B: (A) Presence of a mature biofilm matrix with live and dead microbes of various morphologies at baseline. After four initial cleanings and 6 weekly cleanings with 30 to $40 \mathrm{ppm} \mathrm{ClO}_{2}$, the same line showed removal of biofilm and inorganic deposits in Figure 5B (end of study), but for presence of a scattering of few dead cells

one of these studies demonstrate the efficacy of $\mathrm{ClO}_{2}$ in controlling the biofilm. ${ }^{* *}$

In a recent in vitro study ${ }^{54}$ using various concentrations of hydrogen peroxide for biofilm control, investigators found the biofilms were controlled in the waterlines but removal of inorganic deposits such as the salts coating the lines as a result of municipal water hardness could not be easily removed. Hydrogen peroxide was corrosive at higher concentrations. Figures 7A and B demonstrating presence of salts coating the lines in spite of repeated cleaning of lines with a periodic cleaning agent that removed organic matter including biofilms but could not remove inorganic salts pavementing the lumen of the waterlines. Slaking in the lines may also neutralize the germicidal effects of certain cleaning and decontaminating agents thereby allowing biofilm formation at a faster pace. Therefore, while treating biofilms in the water system, a deslaking agent that is used

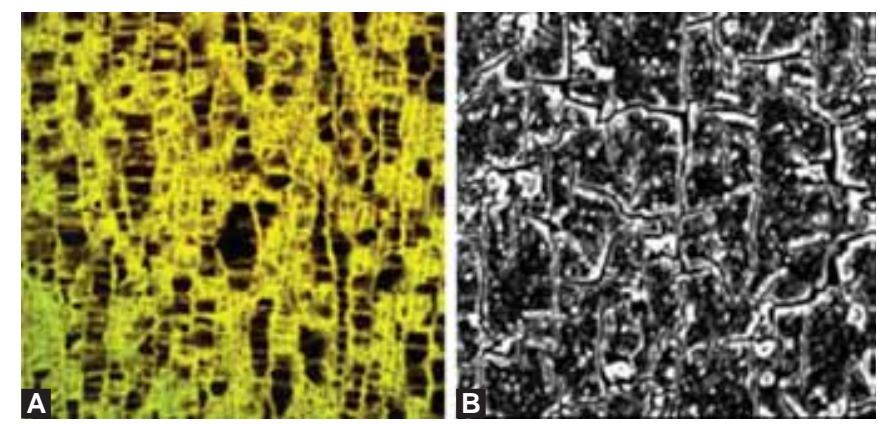

Figs 7A and B: A (Scanning laser confocal microscopy) and (B) (Scanning electron microscopy) absence of biofilms but presence of slaking of the lines

periodically or incorporated within the irrigant may be beneficial.

As of today, the only published numerical standard for dental unit water contamination is set by the Centers for Disease Control and Prevention of the treatment water being $<500 \mathrm{cfu} / \mathrm{ml}^{.53}$ The need for control of biofilms using germicides or other chemical agents has been stated in the guidelines. Protocols in this study were weaker as practitioners felt that rigorous weekly protocols could not be strictly followed in clinical situations and they had concerns of dental equipment damage. This study, as have the previous studies, ${ }^{47,48}$ achieved the $<500 \mathrm{cfu} / \mathrm{ml}$ goal for heterotrophic plate counts irrespective of presence of the amount of biofilms in the waterlines. In this study, dental treatment water in both treatment groups met the CDCs guidelines with treatment unit 1 (using $3 \mathrm{ppm}$ of $\mathrm{ClO}_{2}$ in municipal water as irrigant) being significantly better than the control group $(\mathrm{p}<0.05)$. The mean $\log _{10}$ HPC were $1.61(\mathrm{SD}=0.67)$ for municipal source water, $1.11(\mathrm{SD}=$ $0.22)$ for distilled water, $1.0(\mathrm{SD}=0)$ for treatment unit 1 effluent (consistently $<10 \mathrm{cfu} / \mathrm{mL}$ ), $1.32(\mathrm{SD}=0.44)$ for the treatment unit 2 effluent, and 4.6 $(\mathrm{SD}=0)$ for the control unit effluent. Municipal source water in this 12-week study was not consistently below $500 \mathrm{cfu} / \mathrm{ml}$ and therefore would not be suitable as an irrigant based on the CDCs guidelines. Although treatment unit 2 effluent (citrus botanical irrigant) showed heterotrophic contamination below $500 \mathrm{cfu} / \mathrm{ml}$ throughout the study, its antimicrobial properties are questionable as it did not show the same efficacy as effluent from treatment unit 1 ( $3 \mathrm{ppm} \mathrm{ClO}_{2}$ irrigant). If using the citrus botanical in municipal water as irrigant, it may warrant more frequent periodic shock cleaning of the water system

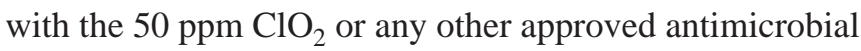
to control biofilms in the lines. Treating the municipal water

\footnotetext{
${ }^{* *}$ These studies have been presented to peer research groups in the United States, such as the American Association for Dental Research, International Association for Dental Research Annual Scientific Sessions or infection control experts at the annual scientific session of the Organization for Safety and Asepsis Procedures.
} 
with $\mathrm{ClO}_{2}$ resulting in 3 ppm concentration, showed significant reduction in contamination in the effluent water in comparison with either the municipal source water or the effluent control $(\mathrm{p}<0.05)$. Multiple comparisons test (Scheffe's post hoc) showed that effluent from the treatment unit 1 was not significantly different from effluent of treatment unit 2 or the distilled source water for the control group ( $p>0.05)$. Both treatment units effluents were significantly better than the control unit's effluent $(\mathrm{p}<0.05)$ and were consistently below $500 \mathrm{cfu} / \mathrm{ml}$ in both 6 -week periods. These results demonstrate effectiveness in both treatment protocols in controlling dental treatment water contamination even when weekly cleaning protocols were not followed.

\section{CONCLUSION}

In this 12-week study, both treatment protocols of multiple initial cleanings and once post 6 weeks with $50 \mathrm{ppm} \mathrm{ClO}_{2}$ in municipal water in combination with either $3 \mathrm{ppm} \mathrm{ClO}_{2}$ in municipal water as irrigant or diluted citrus botanical in municipal water controlled dental unit waterline biofilms and consistently kept effluent water (irrigant/coolant) contamination below $500 \mathrm{cfu} / \mathrm{ml}$. In translation to general clinical use, it may be pragmatic to clean the water system more often to control biofilms. Further, compatibility studies addressing the effects of these chemicals on dental unit water systems and composite bonding to teeth must be conducted in detail prior to broad and common clinical use.

\section{REFERENCES}

1. Peters E, McGaw W. Dental unit water contamination. J Can Dent Assoc 1996;62(6):492-95.

2. Shearer B. Biofilm and the dental office. JADA 1996;127(2): 181-89.

3. Costerton WJ, Cheng KJ, Geensey GG, et al. Bacterial biofilms in nature and disease. Ann Rev Microbiol 1987;41:435-64.

4. Scarbeck K. Dental unit waterlines - curbing infectious midstream. AGD Impact 1993;21(10):6-12.

5. Lizotte JR, Peters E, Whitehouse R. Influence of biofilms on microbial contamination in dental unit water. J of Dent 1991; 19(5):290-95.

6. Sawyer DR, Page DG, Sweeney W, Dalton HP. Bacterial contamination and disinfection of the dental handpiece and the water it delivers. Virginia Dent J 1976;53:14-23.

7. Fitzgibbon EJ, Bartzokas CA, Martin MV, Gibson MF, Graham $\mathrm{R}$. The source, frequency and extent of bacterial contamination of dental unit water systems. Brit Dent J 1984;157(98):98-101.

8. Neff Jh, Rosenthal SL. A possible means of inadvertent transmission of infection to dental patients. J Dent Res 1957; 36:932-34.

9. Blake GC. The incidence and control of bacterial infection in dental spray reservoirs. Brit Dent J 1963;115:413-16.

10. Moriarty JD, Crawford JJ. Evaluation of an independent sterile water reservoir system for highspeed instrumentation. J Dent Res 1976; abstract \#855: B275.
11. Oppenheim BA, Sefton AM, Gill ON, et al. Widespread Legionella pneumophila contamination of dental stations in a dental school without apparent human infection. Epidemiol and Infect 1987;99:159-66.

12. Pankhurst CL, Philpott-Howard JN, Hewitt JH, Casewell MW. The efficacy of chlorination and filtration in control and eradication of Legionella from dental chair water systems. J of Hosp Infect 1990;16:9-18.

13. Mills SE, Lauderdale PW, Mayhew RB. Reduction of microbial contamination in dental units with povidone-iodine 10\%. JADA 1986;113:280-84.

14. Speller DCE, Stephens ME, Viant AC. Hospital infection by Psedomonas cepacia. Letters to the editor. Lancet 1971;17:798.

15. Sorrell WB, White LV. Acute bacterial endocarditis caused by a variant of the genus Herrella. Amer J Clin Path 1953;23:134.

16. Basset DCJ, Stokes KJ, Thomas WRC. Wound infection with Pseudomonas multivaorans: A water-borne contamination of disinfectant solutions. Letters to the editor. Lancet 1970; 6:1188.

17. Speller DCE. Colonization of dental units by water bacteria. Brit Dent J 1973;135(5):189-90.

18. Schiff J, Suter LS, Gourley RD. Flavobacterium as a cause of bacterial endocarditis. Ann of Intern Med 1961;55:499-506.

19. Lowry PW, Beck-Sague CM, Bland LA, et al. Mycobacterium chelonae infection among patients receiving high-flux dialysis in a hemodialysis clinic in California. J Infect Dis 1990;161: 85-90.

20. Weinberger M, Berg SL, Feuerstein IM, Pizzo PA, Witebsky FG. Disseminated infection with Mycobacterium gordonae: Report of a case and critical review of the literature. Clin Infect Dis 1992;14:1229-39.

21. Costrini AM, Mahler DA, Gross WM, et al. Clinical roentgenographic features of nosocomial pulmonary disease due to Mycobacterium xenopi. Am Rev Resp Dis 1981;123: 104-09.

22. Lowry PW, Jarvis WR, Oberle AD, et al. Mycobacterium chelonae causing otitis media in an ear-nose-and-throat practice. N Engl J Med 1988;319:978-82.

23. Fotos PG, Westfall HN, Snyder IS, Miller RW, Mutchler BM. Prevalence of legionella-specific IgG and IgM antibody in a dental clinic population. J Dent Res 1985;64(12):1382-85.

24. Reinthaler FF, Mascher F, Stunzner D. Serological examination for antibodies against legionella species in dental personnel. J Dent Res 1988;67:942-43.

25. Atlas RM, Williams JF, Huntington MK. Legionella contamination of dental-unit waters. Appl and Environ Microbiol 1995;61(4):1208-13.

26. Fayle SA, Pollard MA. Decontamination of dental unit water systems: A review of current recommendations. Brit Dent 1996; 181:369-72.

27. Samaranayke LP, Scheutz F, Cottone J. Infection control for the dental team. Copenhagen Munksgaard 1991;98-99.

28. Samaranayke LP. Handpiece and waterline decontamination and HIV transmission: A critique. Dent Update 1993;20:53-56.

29. US Department of Health and Human Services Recommended Infection Control Practices for Dentistry. MMWR 1993;42: no. RR-8.

30. Williams JF, Johnston AM, Johnson B, Huntington MK, Mackenzie CD. Microbial contamination of dental unit waterlines: Prevalence, intensity and microbiological characteristics. JADA 1993;124:59-65.

31. Kellet M, Hobrook WP. Bacterial contamination of dental handpieces. J Dent 1980;8:249-53. 
32. Blake GC. The incidence and control of bacterial infection in dental spray reservoirs. Brit Dent J 1963;115:413-20.

33. Abel IC, Miler RL, et al. Studies on dental aerobiology: IV. Bacterial contamination of water delivered by dental units. J Dent Res 1971;50:1567-69.

34. Meiller T, Baqui A, DePaola L, Overholser CD. Disinfection of dental unit waterlines using Listerine antiseptic. J Dent Res 1995;74:153.

35. Puttaiah R, Slattery P, Plamondon TJ, Mills SE, Cottone JA. Effects of two different source waters and cleaning dental unit water systems. J Dent Res 1997;76 (special issue), abstract \#2165:284.

36. Puttaiah R, Mills SE, Plamondon TJ, Thrash WJ, Cottone JA. A multigroup longitudinal study of dental unit waterline contamination. J Dent Res 1996;75 (special issue), abstract \#3176:414.

37. Puttaiah R, Waggoner MB, Sherman LE, Bryan WR, Kim PJ. Efficacy of citric acid in controlling biofilms in dental unit waterlines. J Dent Res 1998;77 (special issue), abstract\#1759: 851.

38. Puttaiah R, Cederberg R, Wneck R. Efficacy of chlorhexidine in controlling biofilm contamination of dental unit waterlines. $\mathrm{J}$ Dent Res 1998; 77 (special issue A), abstract \#1255: 262.

39. Puttaiah R, Siebert J, Chen P. Release of disinfection-byproducts during $\mathrm{NaOCl}$ use on contaminated dental unit water systems. Annual meeting of the Organization for Safety and Asepsis Procedures, Providence, RI, abstract \#9807; June 1821, 1998.

40. Puttaiah R, Siebert J, Cederberg R, Spears R. Effects of chlorine compounds on dental waterline biofilms and treatment water. Organization for Safety and Asepsis Procedures, 1999 Annuals Scientific Session, June 24, Cincinnati, OH (abstract and presentation).

41. WHO Library Cataloguing-in-Publication Data, (C) World Health Organization 2002, chlorine dioxide (gas), [Concise international chemical assessment document (CICADs), 37] (1.Chlorine compounds - toxicity; 2.Oxides - toxicity; 3.Risk assessment; 4.Occupational exposure I.International Programme on Chemical Safety II.Series) ISBN 924153037 5, (NLM Classification: QD 181.C5); ISSN 1020-6167.

42. US Environmental Protection Agency - Pesticides Topical and Chemical Fact Sheets. http://www.epa.gov/pesticides/factsheets/ chemicals/chlorinedioxidefactsheet.htm

43. Whitney EAS, Beatty ME, Taylor TH Jr, Weyant R, Sobel J, Arduino MJ, et al. Inactivation of Bacillus anthracis spores. Emerg Infect Dis [serial online] 2003 Jun [date cited]. Emerging Infectious Diseases, June 2003;9(6). Available from: URL: http:/ /www.cdc.gov/ncidod/EID/vol9no6/02-0377.htm

44. MB-10 Chlorine Dioxide Tablets, Quip Laboratories Inc. 1500 Eastlawn Ave, Wilmington, DE 19802, USA.

45. Griffiths PA, Babb JR, Fraise AP. Mycobactericidal activity of selected disinfectants using a quantitative suspension test. Journal of Hospital Infection 1999;41:111-21.

46. Coates D. An evaluation of the use of chlorine dioxide (Tristel One-Shot) in an automated washer-disinfector (Medivator) fitter with a chlorine dioxide generator for decontamination of flexible endoscopes. Journal of Hospital Infection 2001;48:55-65.

47. Nicoara P, Kern D, Lin S, Svoboda J, Spears R, Thomas AC, et al. Control of dental unit water system and treatment water contamination with chlorine dioxide. AADR 2003 Annual Scientific Session, San Antonio, Texas, USA.

48. Puttaiah R, Svoboda K, Spears R, Lin S, Kern D, Thomas AC. Comparison of 4 dental unit waterline cleaners in controlling biofilms and treatment water contamination. AADR 2003 Annual Scientific Session, San Antonio, Texas, USA.

49. Puttaiah R, Mills SE. Research model addressing policy issues for the dental unit water system. 1995 conference on pharmaceutical science and technology, in conjunction with the 26 annual meeting of the fine particle society. 08/26/1995, Chicago, IL.

50. Puttaiah R, Chandler J, Cederberg *R, Spears R. Treatment water contamination control using microfiltration, redox potential and a natural citrus botanical. AADR 2001 Scientific Session, Chicago, IL.

51. Puttaiah R, Griggs J, Parekh J, Sargent C. Effects of $\mathrm{ClO}_{2}$ on dentin and enamel shear bond strength. IADR 2002 San Diego CA.

52. Puttaiah R, Griggs J, Cederberg R, Chandler J. Effects of VistaClean dental waterline irrigant on dentin bonding. IADR 2002 San Diego CA.

53. Centers for Disease Control and Prevention. Guidelines for infection control in dental health-care settings - 2003. MMWR 2003;53(RR-17):1-76.

54. Puttaiah R, Lin S, Giletto A, Svoboda KKH. Efficacy of $\mathrm{H}_{2} \mathrm{O}_{2}$ in controlling dental unit water system contamination. Annual Scientific Session of the American Association for Dental Research, Orlando, Florida 2006. Abstract \# 0639.

\section{ABOUT THE AUTHORS}

\section{Ritu Bansal}

Graduate Student, Masters Program in Public Health, University of Texas Houston School of Public Health, Dallas Branch, Dallas Texas, USA

\section{Raghunath Puttaiah (Corresponding Author)}

Associate Professor, Diagnostic Sciences, Baylor College of Dentistry Texas A\&M University System Health Science Center, 3302 Gaston Ave, Dallas, Texas, USA, e-mail: rputtaiah@bcd.tamhsc.edu

\section{Robert Harris}

Associate Professor, University of Texas Houston School of Public Health, Dallas Branch, Dallas, Texas, USA

\section{Anil Reddy}

Assistant Professor, Pediatric Dentistry, Baylor College of Dentistry Texas A\&M University System Health Science Center, Dallas Texas, USA 